\title{
OPERATOR MONOTONE FUNCTIONS OF SEVERAL VARIABLES
}

\author{
FRANK HANSEN
}

Abstract. We propose a notion of operator monotonicity for functions of several variables, which extends the well known notion of operator monotonicity for functions of only one variable. The notion is chosen such that a fundamental relationship between operator convexity and operator monotonicity for functions of one variable is extended also to functions of several variables.

Mathematics subject classification (2000): 26 B99.

Key words and phrases: Operator monotone functions.

\section{REFERENCES}

[1] H. ARAKI AND F. HANSEN, Jensen's operator inequality for functions of several variables, Proc. Amer. Math. Soc., 128 (2000), 2075-2084.

[2] J. Bendat And S. Sherman, Monotone and convex operator functions, Trans. Amer. Math. Soc., 79 (1955), 58-71.

[3] F. HANSEN, An operator inequality, Math. Ann., 246 (1980), 249-250.

[4] F. HAnsen, Operator convex functions of several variables, Publ. RIMS, Kyoto Univ., 33 (1997), 443-463.

[5] F. HANSEN, Operator inequalities associated with Jensen's inequality, In T. M. Rassias, editor, Survey on Classical Inequalities, pages 67-98. Kluwer Academic Publishers, 2000.

[6] F. HANSEN, Convex trace functions of several variables, Linear Algebra Appl., 341 (2002), 309-315.

[7] F. HANSEN AND G.K. PEDERSEN, Jensen's inequality for operators and Löwner's theorem, Math. Ann., 258 (1982), 229-241.

[8] R. V. KADISON AND J. R. RINGROSE, Fundamentals of the Theory of Operator Algebras, I-II, Academic Press, $1982 \& 1986$.

[9] A. KORÁNYI, On some classes of analytic functions of several variables, Trans Amer. Math. Soc., 101 (1961), 520-554.

[10] E. Lieb And G. K. Pedersen, Convex multivariate trace functions, Rev. Math. Phys., 14 (2002), 631-648.

[11] R. MATHIAS, Concavity of monotone matrix functions of finite order, Linear and Multilinear Algebra, 27 (1990), 129-138.

[12] G. K. PEDERSEN, Convex trace functions of several variables on $C^{*}$-algebras, J. Operator Theory (to appear).

[13] M. Singh AND H. L. VASudeva, Monotone matrix functions of two variables, Linear Algebra Appl., 328 (2001), 131-152. 